\title{
Why are we here? An Investigation of Academic, Employability and Social Facets of Business Undergraduates' Motivation Using Thurstone Scaling
}

\author{
By John Buglear*
}

In the UK employability is a key university performance measure. This reflects both the tightening graduate employment market and the demands on the sector for greater accountability. The literature on employability considers the implications for institutions and the student motivation literature examines students' intrinsic and extrinsic goal orientations. This exploratory study complements both areas of work by considering employability, currently deemed an allpervasive extrinsic goal, as far as students' motivation is concerned relative to the more conventional drivers of decisions to enter higher education; achieving academic success and social fulfilment. It aims to establish both the significance of employability as a motivating factor and ascertain the degree of association with the academic and social factors as well as profile variables. The research design applies Thurstone attitude scaling. Several hundred business undergraduates were asked to encapsulate why they were on their course. The responses were collated and scored by a set of judges against scales of academic, employability and social motivation. The judges' scores were used to determine the most appropriate statements to use in the research instrument, which was then used to survey the attitudes of 75 students. The results suggest that employability is a significant aspect of students' motivation and is associated with the academic and social aspects of motivation. This significance of employability suggests effective learning support strategies are likely to be those that are based on experiential and skill-driven learning alongside more tightly drawn cognitive approaches. The balance of motivational aspects can also inform institutions' student recruitment.

${ }^{*}$ Head of the Management Division, Nottingham Business School, Nottingham Trent University, UK. 


\section{Introduction}

'Employability' has long been an implicit outcome of the UK higher education sector. Yorke traces the association between higher education and labour market outcomes back to 1963 (2004: 409). Knight and Yorke argue that ' $U K$ higher education institutions [...] are now charged with promoting graduate employability - contributing directly to the stock of human capital and their performances are monitored' (2003: 3) and Tomlinson notes that degrees 'have been presented as crucial for economic development' (2008: 49). From September 2012 English institutions must provide publicly accessible Key Information Sets (KIS) for potential applicants. These will contain data about employment, including occupational status six months after graduation, the proportion of graduates in 'graduate jobs' and pay levels (Department for Business Innovation \& Skills, 2011: 28-29).

\section{Employability and Student Motivation}

Notwithstanding the current emphasis on employability there is no clear consensus about its meaning. Pool and Sewell (2007: 277) refer to 'this elusive concept of employability' and Tymon (2011:2) records the 'lack of coherence about what is meant by the term'. After noting the 'various definitions' Saunders and Zuzel (2010) adopt Yorke's formulation of employability as ' $a$ set of achievements - skills, understandings and personal attributes - that makes graduates more likely to gain employment and be successful in their chosen occupations, which benefits themselves, the workforce, the community and the economy' (2006: 8). This is student-focussed, epitomising what Wilton describes as 'the policy emphasis on the supply-side of the labour market' (2008: 18) and anticipates employability being aligned with student motivation. It follows that the significance of employability within students' disposition to enter higher education is key.

In his study of 350 management students Adcroft employs the psychological dichotomy of extrinsic and intrinsic motivation. He contrasts the extrinsic, study as a means to an end, with the intrinsic, study for its own sake (2010: 12). Rolfe (2001: 2) found in her interviews with 70 lecturers at four UK universities that the balance between the extrinsic and intrinsic had changed during her respondents' careers. They felt that a 'higher proportion of current students go to university for career reasons than in the past' and that 'students are less interested in their subject and are more interested in vocational aspects of their studies'. This contrasts somewhat with the findings from the survey of 300 marketing students at a Malaysian institution by Ting and Lee (2011: 12). They explored the rationales students deployed in choosing options. They found that 'perceived exposure to future career skills is not the most important attributes for students in choosing elective subjects'. In their literature review they note that although there is some congruence between criteria applied for option choice and selection of institution and course 'most 
of the criteria used to choose their electives do not seem to concur with the goal of choosing an institution which offers a quality education that would ultimately help secure potential career opportunities' (2011: 2).

Kember et al. interviewed 36 undergraduates at Hong Kong universities to explore their motivation (2008: 316). They applied the notion of 'orientation' to encapsulate the mix of student motivations (2010: 264) and regarded motivation as 'a multifaceted phenomenon' (2010: 265). Their 'motivational orientation framework' consisted of six continua including career, which may be considered to align with employability, interest, suggesting a focus on the academic dimension of the student experience, and 'university lifestyle' and 'sense of belonging', both reflecting the social dimension of it (2010: 265). As far as the career dimension was concerned they identified two aspects, 'it was common to see a degree as a prerequisite to a reasonable career [but] most students were also guided in their choice of [...] programme [...] by career prospects' (2010: 275). Their findings on the academic aspect were that although 'some students thought little about going to university, for others there was a strongly expressed personal goal of taking their education as far as they could' (2010: 275). One of their social aspects, 'university lifestyle', constituted 'a motivation for students to attend university through the social life universities offered' (2010: 275).

The social dimension emerged as a significant factor in Clewes' interviews with ten students on a UK MBA programme. She found that 'student-tostudent interaction was seen as a particularly satisfying aspect [...] by the majority of the informants' (2003: 80). This finding confirmed other studies she cited as highlighting 'the importance of student interaction and the social climate' (2003: 83).

The academic components of the Kember et al. model (2010: 265) and the work of Clewes (2003) echo the model advanced by Tinto in his influential work on student retention. In this he identified congruence with the academic and social domains of their institution as crucial to student persistence (1975: 94).

The themes outlined above provide the foundation for the work reported here. The research questions that it seeks to address are:

1. How strong is employability as an aspect of student motivation to enter higher education?

2. How does the employability aspect of motivation vary by gender, course mode and whether or not English is the student's first language? This last variable is used as a loose proxy of international versus home students, although it is conceded that language is not the sole discriminating factor between home and international students.

3. To what extent and how is the employability aspect of motivation related to the academic and social aspects of motivation? 


\section{Research Methods}

The departure points for the literature on employability have been governmental (Knight and Yorke, 2003: 3), supra-governmental (Yorke, 2004: 410) and the three perspectives listed by Tymon; employer, student and institution (2011: 2). Tymon concentrates on the nature of employability from the student perspective (2011: 12).

This study was undertaken in the business school at Nottingham Trent University, a UK institution with approximately 25,000 students on a wide variety of courses. It adopts a broad, grounded basis (Fisher, 2010: 137), applying a 'bottom-up' rather than 'top-down' approach by starting with students' rationales for entering higher education. In May 2011, 282 business undergraduates were asked to state in a single sentence why they had come to university. A total of 386 statements were submitted, some students writing down more than one. These were the raw materials for the research instrument.

The statements were categorised into 'academic' e.g. 'I wanted to get a university education', 'employability' e.g. 'I want to improve my job prospects for the future' and 'social' e.g. 'I came here for the good night life'. Approximately $30 \%$ of the statements were academic, $53 \%$ employability and $17 \%$ social.

Actual or close duplicates were removed and the remaining statements listed in three files, one each for the academic, the employability and the social. Following Thurstone's method of equal appearing intervals (Trochim, 2002), developed as a way of measuring psychological value (Thurstone, 1929: 157) and commended by Oppenheim as an appropriate method of studying differences between groups (1992: 189), these statements constituted the 'pool of items' for rating by judges (Oppenheim, 1992: 190). The dozen judges used in the study included tutors, academic support staff and students. Each was asked to rate each statement on a scale from the least positive (1) reason for going to university to the most positive (11). This process was repeated for the three files.

The central tendency and spread of the judges' scores for each statement were used to select a set of statements for the instrument. Following Oppenheim (1992: 194) the statements were grouped by average score and the one among the several with the same average having the least spread was selected as the statement reflecting that point on the scale. For five of the 87 academic statements the median of the judges' scores was 1 . Of these five the one with the least spread of judges' scores was 'I am on this course because it was the easiest option' so this statement was selected for the instrument to reflect the point 1 , the least positive on the scale for the academic aspect of motivation to enter higher education. The same process resulted in 'I am on this course because I find the constant evolution of business and the new concepts fascinating' being chosen to reflect the other end of this scale, in this case 10 as no statement achieved a median judges' score of 11 .

The equivalent polar statements for employability were 'I am on this course because I want to be a millionaire' (1) and 'I am on this course for a 
solid grounding to proceed with my future career and learn new skills I will benefit from for the rest of my life' (10). For the social aspect they were 'I didn't really want to go to university but my teachers pushed me into it' (1) and 'I came here because being at university is a life experience' (10).

Ten statements for each aspect were sifted from each of the three original sets. Collectively the ten constitute the calibrations on a 10-point scale. For the instrument, the sequence of the statements in each of the three sets of ten was randomised. The final instrument consisted of three profile questions, on gender, mode of study (full-time or sandwich) and whether or not English was the respondent's first language, followed by the thirty selected statements. Respondents were asked to tick only those statements with which they agreed.

This pilot study was a convenience sample survey of second year business undergraduates conducted by direct elicitation which yielded 75 useable responses. The data from these were entered into the Minitab package. The responses to the profile questions were analysed directly. The responses to the statements were used to generate an average score for each of the three motivational aspects by adding the score for each statement with which a respondent had agreed and dividing by the number of statements with which they had agreed, following Trochim (2002). To illustrate, one respondent, a female on a full-time courses whose first language was not English agreed with the academic aspect statement rated 2, the two employability aspect statements rated 6 and 8 , and the three social aspect statements rated 6,8 and 10. These yield an average academic aspect score of 2, an employability aspect score of 7 and a social aspect score of 8 .

Oppenheim contends that the reliability of Thurstone scales 'tends to be adequate', and offers a similar qualified endorsement of their validity (1992: 194-5). The robustness of the method rests substantially on the a priori objectivity afforded by the role of the judges.

\section{Findings}

Of the 75 respondents, $31(41.3 \%)$ were female, $50(66.7 \%)$ were on a sandwich course and $35(46.6 \%)$ did not have English as their first language. Contingency analysis showed no significant association between Gender and Mode ( $\mathrm{p}=0.097)$ but significant association between Gender and English as a first language $(p=0.033)$; a higher than expected number of males and a lower than expected number of females having English as their first language. Mode and English as the first language were very significantly associated $(p=0.000)$ with more sandwich and fewer full-time students than expected having English as their first language.

The employability aspect scores, plotted against the scale range of 0 to 10 are shown in Figure 1, with a normal curve superimposed on the distribution. The scores have a mean of 6.27 and a standard deviation of 1.31 . 
Figure 1: Histogram of Employability aspect scores

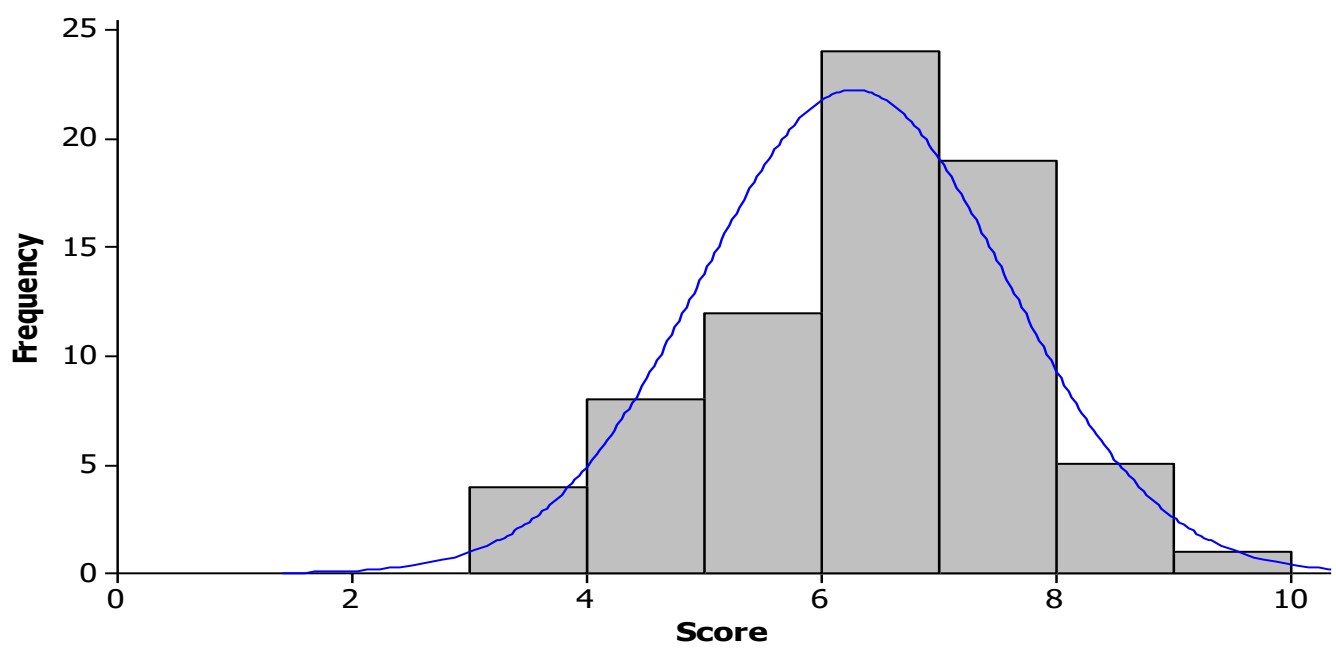

The distributions of employability aspect scores by gender are shown in Figure 2. The line between the two plots connects the mean of the females' scores with that of the males' scores. The females' mean score, 6.64 is significantly higher than the males' mean score, 6.01 and there is a wider spread of females' scores with a standard deviation (s.d.) of 1.35 compared to 1.23 for the males' scores. The two-sample $t$ test revealed that the difference between the means is marginally significant $(\mathrm{p}=0.049)$.

Figure 2: Boxplot of Employability aspect scores by Gender

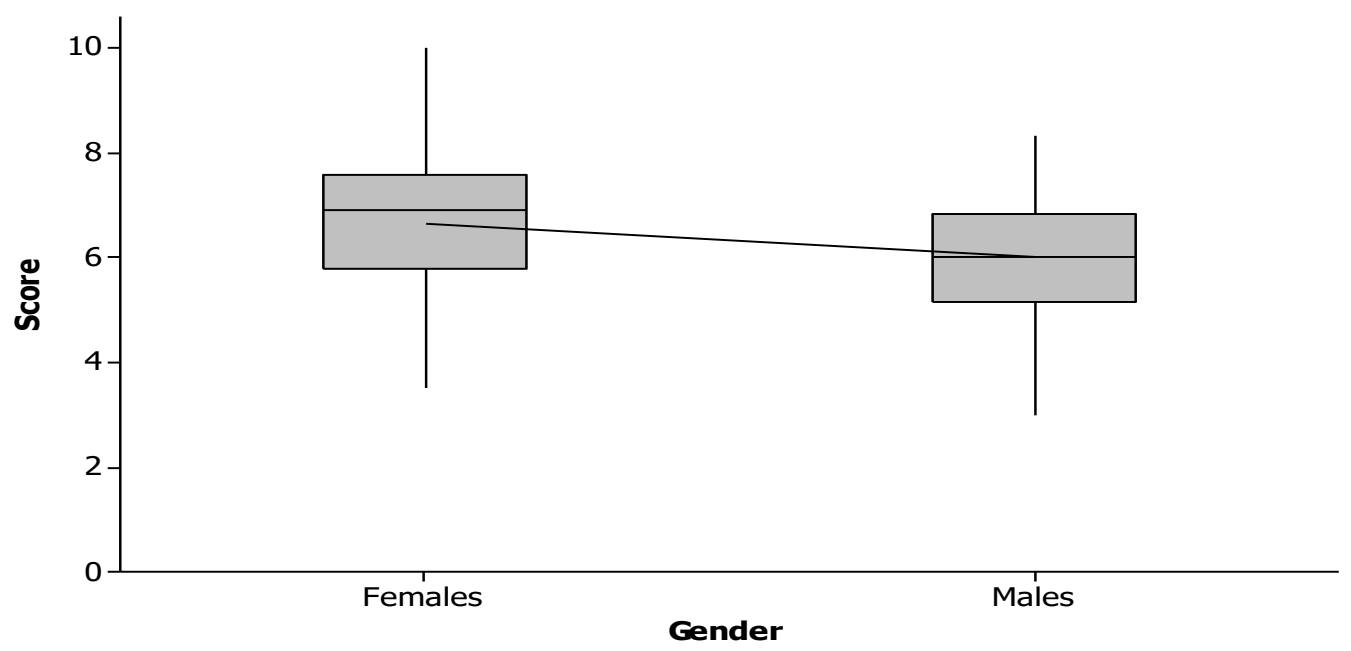

Figure 3 shows the distribution of employability aspect scores by mode of study. The mean of the full-time students' scores at 6.23 is close to that of the sandwich students', 6.35 and the difference is not significant $(p=0.711)$. The spread of full-time students' scores is more $($ s.d. $=1.37)$ than for the sandwich students (s.d. $=1.20)$. 


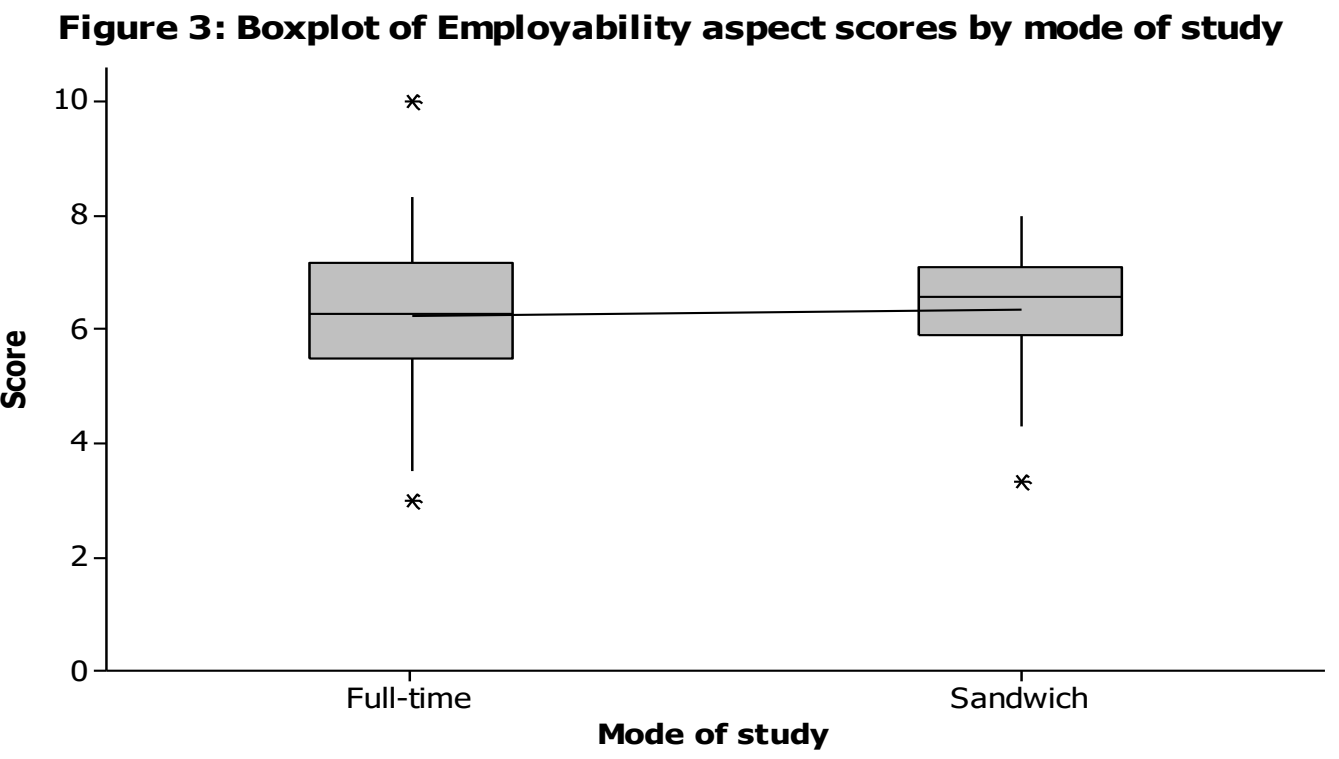

Figure 4 shows the employability aspect scores by the first language variable. The mean scores of those not having English as a first language, 6.45 is higher than those for whom English is the first language, 6.12, but the difference is not significant $(\mathrm{p}=0.312)$. There is a greater spread of scores for those for whom English is not their first language (s.d. = 1.47) than for the native English speakers (s.d. $=1.15$ ).

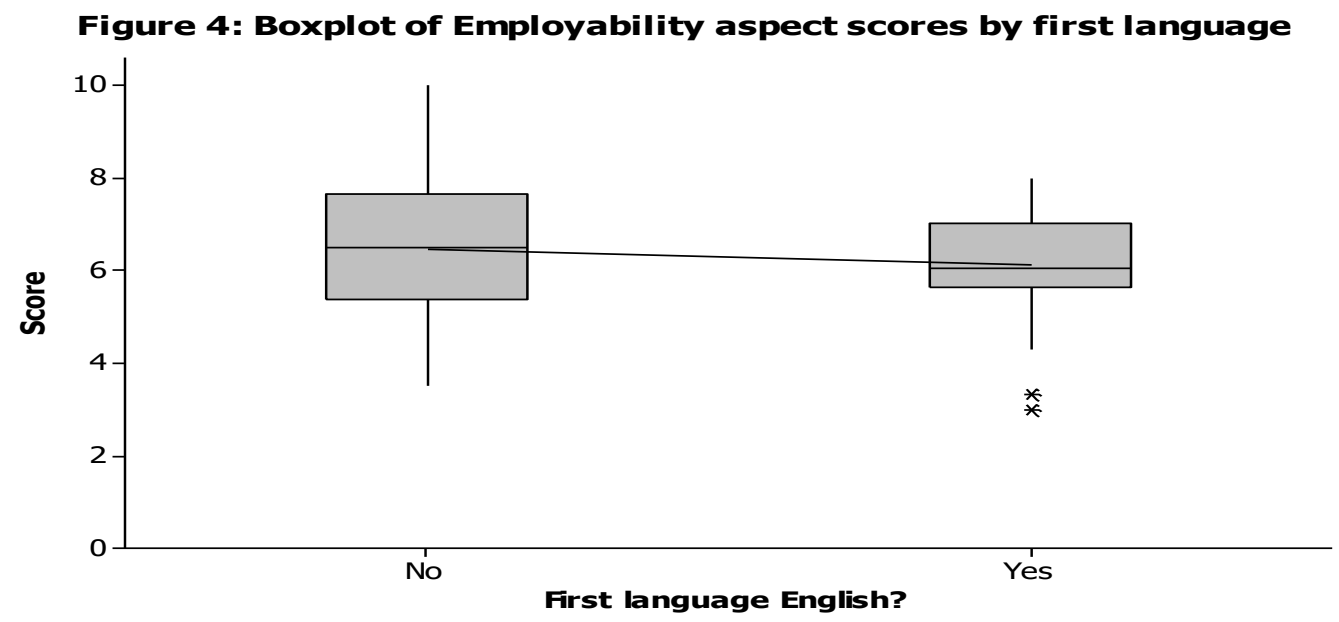

The distribution of the Academic aspect scores is portrayed in Figure 5. The distribution has a mean of 6.69 and a standard deviation of 1.37. The mean score of the females is higher (6.97) than that of the males (6.49) but the difference between them is not significant $(\mathrm{p}=0.166)$. The spread of females' scores is greater $($ s.d. $=1.68)$ than for the males' scores (s.d. $=1.08)$. The mean score of sandwich students is higher (7.08) than for full-time students (6.49) and the difference is of marginal significance $(\mathrm{p}=0.066)$. The spread of scores 
is lower for sandwich students (s.d. = 1.19) than for full-time students (1.43). The mean score of those for whom English is not their first language (6.53) is less than that of those for whom it is $(6.83$, but not significantly so $(\mathrm{p}=0.354)$. The spread of scores is higher for those not having English as their first language (s.d. $=1.58$ ) than for the native English speakers (1.16).

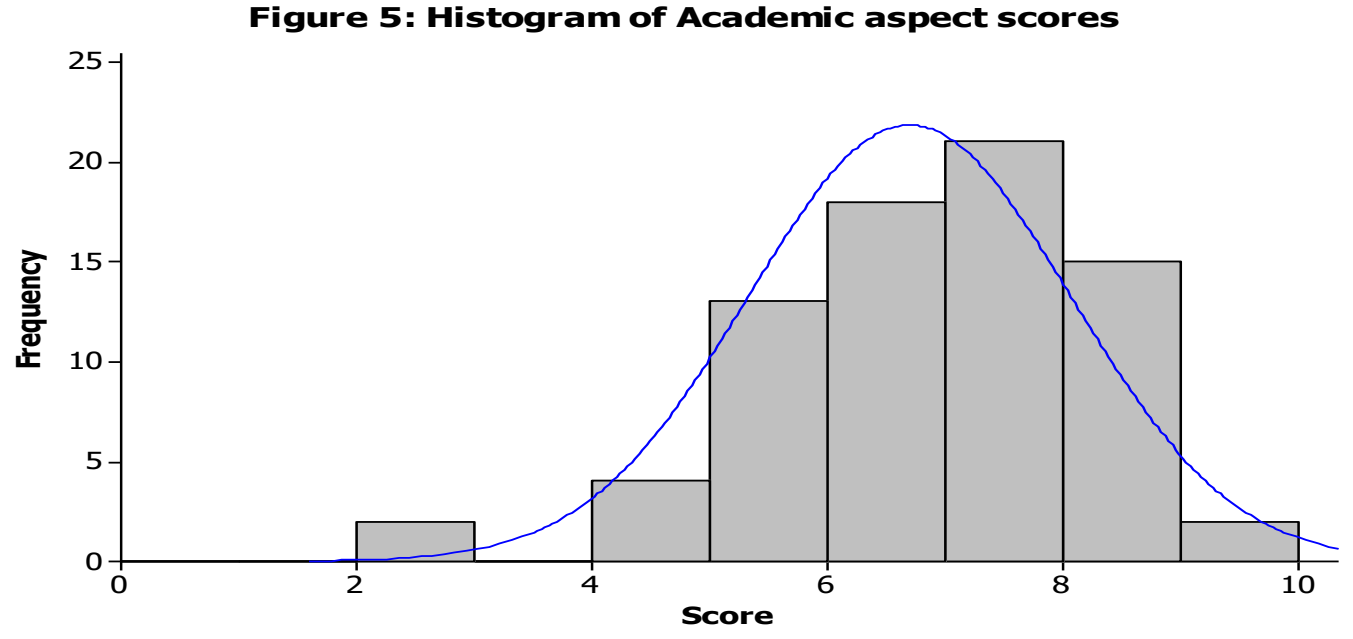

Figure 6 portrays the social aspect scores. This distribution has a mean of 7.08 and a standard deviation of 1.31 . For this aspect the mean score of the females is higher (7.38) than that for males (6.87) although not significantly so ( $\mathrm{p}=$ $0.122)$. The spread among female scores is higher (s.d. $=1.46)$ than for the male scores $($ s.d. $=1.16)$. Full-time students' scores have a higher mean $(7.18)$ that those of sandwich students but difference is not significant $(\mathrm{p}=0.411)$. The spread in sandwich student scores is more (s.d. = 1.43) than in full-time student scores (1.24). The difference between the mean score of students who have English as their first language (7.14) is very slightly less than the mean score of student who do not (7.02) and this difference is not significant so ( $\mathrm{p}=$ $0.711)$.

Figure 6: Histogram of Social aspect scores

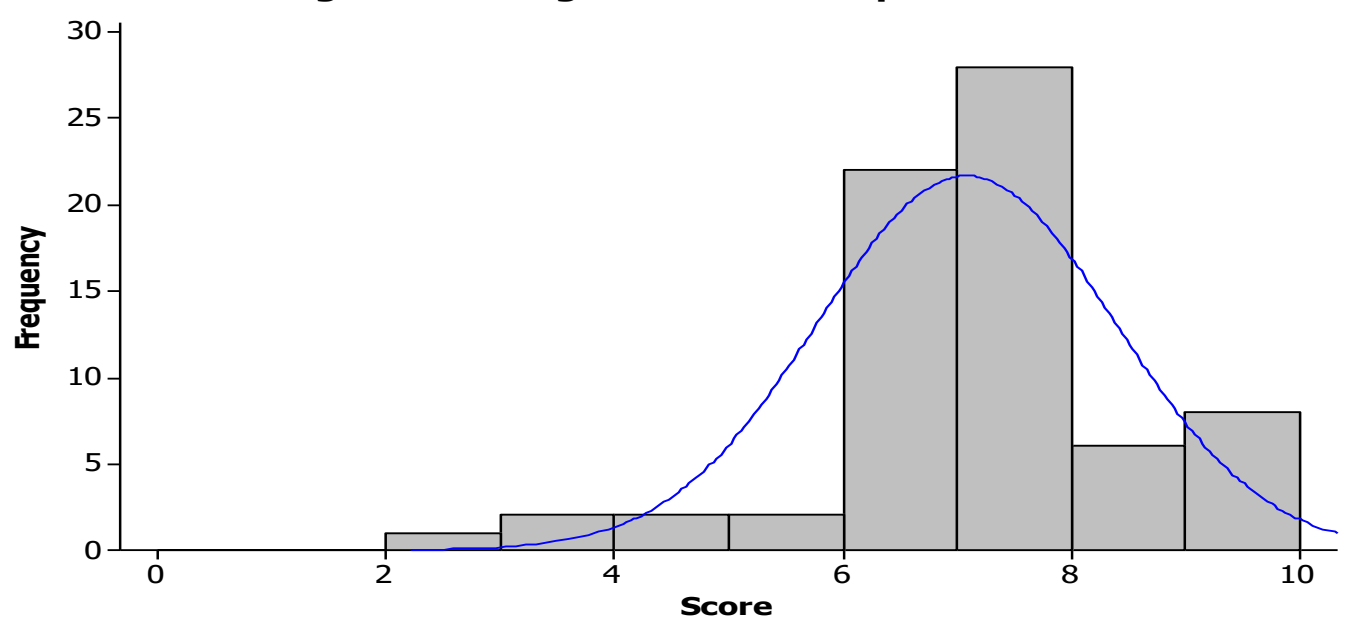


Figure 7 compares the distributions of Academic, Employability and Social aspect scores. The results of one-way ANOVA of these data suggest that the difference between the mean scores for the academic, employability and social aspects, 6.69, 6.27 and 7.08 respectively is significant $(p=0.001)$, which arises from the contrast between the mean scores of the employability and social aspects.

Figure 7: Boxplot of Academic, Employability and Social aspect scores

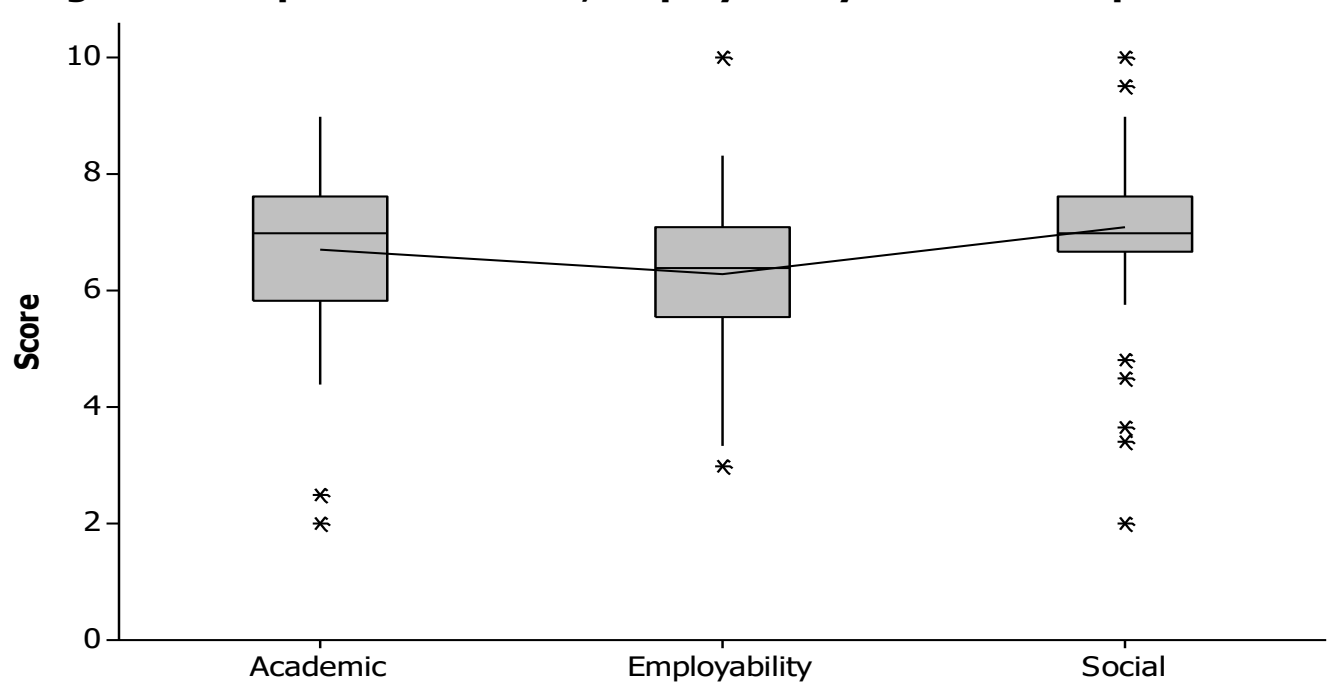

ANOVA investigates the data as independent samples. An alternative approach is to use paired t testing since each student generated more than one score and hence the differences between the scores by aspect can be probed more effectively by analysis based on matched pairs.

The results of the paired $t$ tests are summarised in Table 1 . They confirm the findings from ANOVA in that the most significant contrast is apparently between the Employability and Social aspect scores, with the Employability aspect scores on average lower than the Social aspect scores. The distribution of differences between these scores is portrayed in Figure 8.

Table 1. Paired t Test Results by pairing of Aspect Scores

\begin{tabular}{|c|c|c|}
\hline Aspect score difference & Mean difference & Significance (p) \\
\hline $\begin{array}{c}\text { Academic - } \\
\text { Employability }\end{array}$ & 0.406 & 0.047 \\
\hline Academic - Social & -0.388 & 0.070 \\
\hline Employability - Social & -0.843 & 0.000 \\
\hline
\end{tabular}




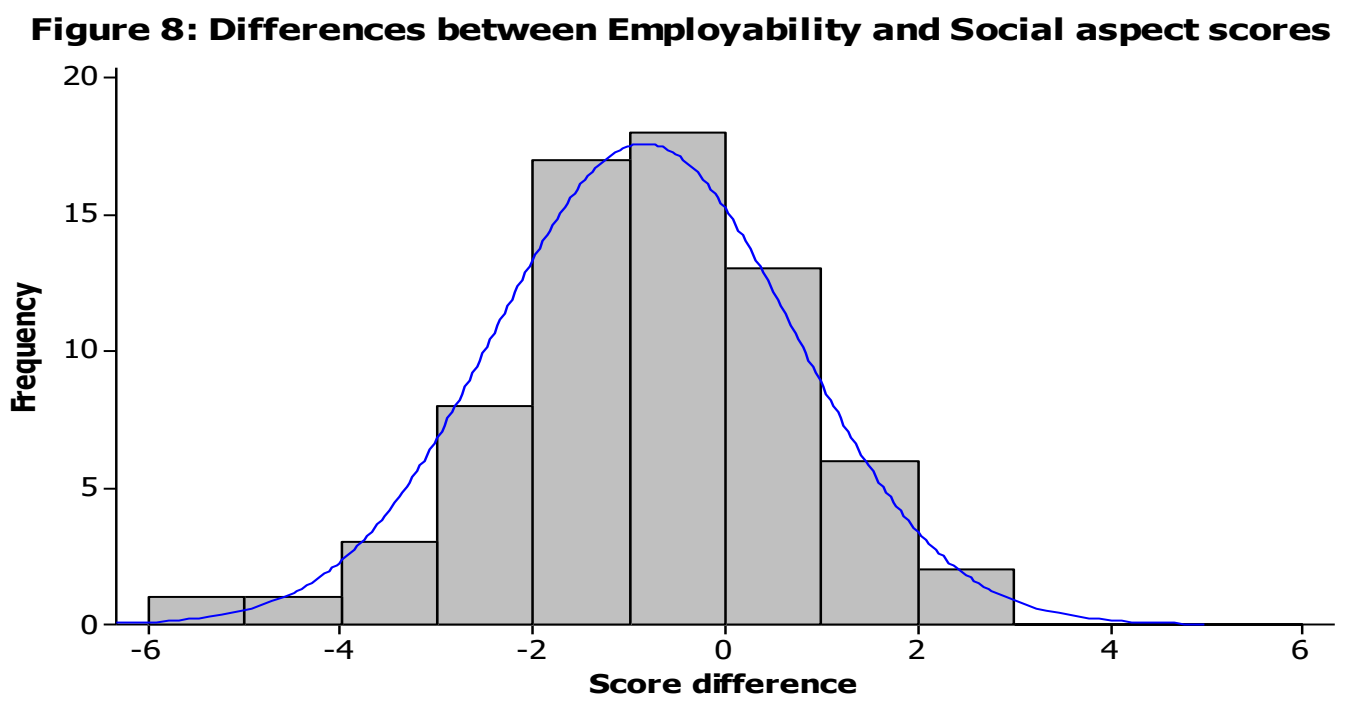

\section{Discussion}

The results above indicate that Employability is an important aspect of students' motivation to go to university. The scores for this aspect are lower than for the other two aspects measured here although not dramatically so even where the differences are statistically significant. This concurs with Kember et al. reporting 'co-existence of the interest and career facets as positive poles' in student motivation (2010: 265) and that interest acted in concert with the career aspect, as students expected their degree to lead to a reasonable career and interest them too.' (2010: 275).

The Employability aspect scores are in general higher for females than males and for those whose first language is not English than for native English speakers. The association between gender and whether or not English is the student's first language, with females proportionately more numerous among those not having English as their first language influences these results.

The lack of significance in the Employability aspect scores between fulltime and sandwich students is perhaps surprising as sandwich students might well be regarded as prioritising Employability by virtue of the placement element of their choice of course. This result is not so surprising when the association between mode and the language variable is taken into account. Those not having English as their first language have in general higher scores yet proportionately fewer are on sandwich courses. The language factor seems to exert a balancing effect.

The Academic aspect scores do not appear to be significantly distinguishable by any of the three profile variables. The Social aspect scores are in general higher for females than males but there is no evident significant difference on the basis of mode or language. This last result implies that international students have broadly the same social motivation for joining their 
course. Whether or not their aspirations in this respect are fulfilled is of course another matter.

There are some important caveats that should be attached to the consideration of these results. These concern the instrument design, the empirical process and the analysis.

The three aspects measured here are composite in nature, and this is especially so in terms of the Social aspect. This affected how the judges scored the statements for this aspect. The Academic aspect contains within it strands of interest in the subject as well as academic performance and fulfilment of potential. The Employability aspect embraces both aspiration for specific career paths and the hope of finding career paths. These disparities did not impact on the judges' scoring process as much as was the case for their scoring of the Social aspect statements. There was in general a wider variation in the judges' scores for the statements associated with this aspect, and this reflected fundamental differences on what constituted legitimate social components of life at university. This was sharpest in the rating of statements about the seeking of personal relationships, with some judges considering such activities to be very negative and others that it was very positive, in the sense that it could bring stability to a student's university work and focus ambition. The effect of this disparity of view was that none of the statements about personal relationships attracted sufficiently consistent scores to be used in the instrument.

The questionnaire was distributed in seminars for one second-year undergraduate module by the seminar tutor, completed during the seminar and returned to the tutor. There are three empirical complications that arise from this. The first is that in using tutors for elicitation, students' responses may be shaped by wishing to report what they believe the tutor wants them to say rather than what they actually think.

The second issue arises because not all students belonging to the seminar groups attended the seminars at the questionnaires were distributed. This is arguably a form of non-response that may inject bias into the findings. As Moser and Kalton contend, 'non-response is a problem because of the likelihood - repeatedly confirmed in practice - that people who do not return questionnaires differ from those who do' (1993: 267-268). The insight that Moser \& Kalton suggest might be gleaned about non-respondents from the likelihood of their responses being closer in nature to those of respondents replying to a follow-up, as against the initial request (1993: 267) which was not available in this case as there was only one round of elicitation. It is reasonable to surmise that the inevitable lack of response from non-attenders does give rise to bias as their absence may well reflect a lower motivation on their part. If this were the case the distributions of scores for the motivational aspects are likely to be different from those that would have occurred had all target respondents been reached. Arguably the average Academic aspect score may have been lower, although the average Social score might have been higher. It 
is difficult to conjecture what impact a $100 \%$ response would have had on the average Employability aspect score.

The third empirical issue arises from the survey being of second-year undergraduates. These, it might be argued have already experienced a year of higher education during which by peer pressure and institutional socialisation they have absorbed institutional and tutor perspectives that impact on their own motivational dispositions. This could render a compression effect on the distributions of scores resulting in tighter distributions than might arise from a survey of first-year students, especially as by the second year of study, students with lower motivation may well be among those who have left voluntarily or by virtue of inadequate academic performance.

The analysis of the scores reported above relies on parametric statistical summary measures, the mean and the standard deviation. The scores data are measured on a relative rather than an absolute scales such as those used to measure time or distance, making them ordinal in nature and thus in strict terms analysed more appropriately non-parametric methods (Blumberg et al., 2005: 276). The deviation from that orthodoxy is conventionally excused by virtue of the power of parametric methods being generally greater than as nonparametric methods (Blumberg et al., 2005: 276) and hence the fact that 'researchers frequently 'bend the rules' in order to be able to use parametric techniques' (Oppenheim, 1992:.158). It might also be argued that the wider understanding of parametric methods and the relative obscurity of nonparametric methods also influences this practice. The adoption of it here is undertaken in line with Kerlinger's advice that 'the best practice would seem to be to treat ordinal measurements as though they were interval measurements but to be constantly alert to the possibility of gross inequality of intervals' (quoted in Blumberg et al., 2005, p.376).

These caveats are important qualifications in determining how far generalisation is possible from the results of this study. A further limitation arises from the sampling method used, convenience sampling. This is a generally simple and quick approach to adopt in an exploratory study (Buglear, 2012: 340) but generalising from sample results to the population is not as robust as that achieved by the use of samples selected by a random process (Bryman and Bell, 2011: 185). It does not mean the samples are inevitably unrepresentative, which can occur with random samples, but that what Blumberg et al. call 'estimates of precision' cannot be obtained (2005: 208). The implication is that any inference drawn from the sample results can be no more than speculative and illustrative. In addition the survey was undertaken at specific points in time, like those of Adcroft, 'a series of snapshots of student motivation rather than a moving picture of student motivation' (2012: 19). It is reasonable to speculate that student motivation may be influenced by the stage of the academic year and extraneous factors such as personal difficulties or financial problems.

Taking these issues into account, the scope for generalisation is confined to regarding this study as a single case illustrating a specific feature of the student experience. Silverman argues that such a case, where the context itself 
is broad is of interest (2005: 134) and Mabry contends that it offers the possibility of what he terms 'petite generalisation' (2008: 223).

\section{Conclusion}

As Adcroft argues, 'motivation is an important influence on student learning' (2010:12), and that the 'diversity of motivation' means that there is a challenge in meeting 'the expectations of students whose primary motivation is curiosity and interest, as well as meeting the expectations of those students with a more instrumental mindset' (2010: 19). The results here suggest that the diversity of the academic, employability and social aspects of motivation is reasonably homogenous, with relatively few students recording scores at the extremes of the scales.

The findings suggest there does seem to be a general alignment of student motivation with the employability purpose now prominently imputed to UK higher education. It should however be emphasised that the respondents were business students undertaking a course with a vocational focus, being more study for business than study of business. As such it might well be assumed that their motivation for university study will align with the employability agenda.

This research offers insights into the achievement of the effective blending of the learning experience. The rating of the employability motivation aspect as almost on a par with the academic suggests that the ideal for the students surveyed would be the unity of theory and practice that is typically sought in business education, and especially where an experiential component is available. For student recruitment, the evidence presented here suggests that the inclination of students is be attracted to courses that offer both academic challenge and enhancement of career prospects.

\section{References}

Adcroft, A. (2010). 'The motivations to study of undergraduate students in management: The impact of degree programme and level of study.' International Journal of Management Education 9(1): 11-20

Blumberg, B., D.R. Cooper \& P.S. Schindler (2005). Business research methods. Maidenhead: McGraw-Hill Education

Bryman, A. \& E. Bell (2011). Business research methods. $3^{\text {rd }}$ ed. Oxford: Oxford University Press

Buglear, J. (2012). Quantitative methods for business and management. Harlow: Pearson

Clewes, D. (2003). A student-centred conceptual model of service quality in higher education.' Quality in Higher Education 9(1): 69-85

Department for Business Innovation \& Skills (2011). 'Higher Education: Students at the heart of the system. London: The Stationary Office 
Fisher, C. (2010). Researching and writing a dissertation. $3^{\text {rd }}$ ed. Harlow: Pearson Education

Kember, D., A. Ho \& C. Hong (2010). 'Initial motivational orientation of students enrolling in undergraduate degrees.' Studies in Higher Education 35(3): 263-276

Kember, D., C. Hong \& A. Ho (2008). 'Characterising the motivational orientation of students in higher education: A naturalistic study in three Hong Kong universities.' British Journal of Educational Psychology 78: 313-329

Knight, P. \& M. Yorke (2003). 'Employability and good learning in higher education.' Teaching in Higher Education 8(1): 3-16

Mabry, L. (2008). 'Case study in social research.' In P. Alasuutari, L. Bickman and J. Brannen (eds.), The SAGE Handbook of Social Research Methods, 214-227. London: Sage

Moser, C.A. \& G. Kalton (1993). Survey methods in social investigation. $2^{\text {nd }}$ ed. Aldershot: Ashgate

Oppenheim, A. N. (1992). Questionnaire design, interviewing and attitude measurement. London: Continuum

Pool, L.D. \& P. Sewell (2007). 'The key to employability: Developing a practical model of graduate employability.' Education + Training 49(4): 277-289

Rolfe, H. (2001). 'The effects of tuition fees on students' demands and expectations: evidence from case studies of four universities.' Discussion Paper 190, London: National Institute of Economic and Social Research

Saunders, V. \& K. Zuzel (2010). 'Evaluating employability skills: Employer and student perspectives.' Bioscience Education DOI:10.3108/beej.15.2

Silverman, D. (2005). Doing qualitative research. London: Sage

Thurstone, L. L. (1929). The measurement of psychological value. In: T. V. Smith and W. K. Wright (eds.), Essays in Philosophy by Seventeen Doctors of Philosophy of the University of Chicago. Chicago: Open Court, 157-174.

Ting, D. H. \& C. W. K. Lee (2011). 'Understanding students' choice of electives and its implications.' Studies in Higher Education DOI:10.1080/03075079. 2010.512383: 1-17

Tinto, V. (1975). 'Dropout from higher education: A theoretical synthesis of recent research. Review of Educational Research 45(1): 89-125.

Tomlinson, M. (2008). 'The degree is not enough: students' perception of the role of higher education credentials for graduate work and employability.' British Journal of Sociology of Education 29(1): 49-61

Trochim, W. M. K. (2002). Thurstone scaling. Available at http://www.socialresearch methods.net/kb/scalthur.htm [15 April 2012]

Tymon, A. (2011). 'The student perspective on employability' Studies in Higher Education DOI:10.1080/03075079.2011.604408: 1-16

Yorke, M. (2006). Employability in higher education: What it is - What it is not. York: Higher Education Academy

Yorke, M. (2004). 'Employability in the undergraduate curriculum: Some student perspectives.' European Journal of Education 39(4): 409-427 